\title{
Social Determinants Influence Physician's Behavior in Prescribing Antibiotics: Factors and Consequences
}

\author{
Muhammad Ahmer Raza ${ }^{1,2}$, Shireen Aziz MS ${ }^{3,4}$, Shahid Masood Raza ${ }^{1,4,5 *}$ and Sana Shahzad ${ }^{1,4}$ \\ ${ }^{1}$ Faculty of Pharmacy, The University of Faisalabad, Faisalabad, Pakistan \\ ${ }^{2}$ Department of Clinical Pharmacy, School of Pharmaceutical Sciences, Shandong University, China
}

${ }^{3}$ School of Pharmacy, Zhengzhou University, China

${ }^{4}$ Faculty of Pharmacy, University of Sargodha, Pakistan

${ }^{5}$ School of Pharmacy, Tongji Medical College, Huazhong University of Science and Technology, China

*Corresponding author: Shahid Masood Raza, B Pharm School of Pharmacy, Tongji Medical College, Huazhong University of Science and Technology, Wuhan 430030, Hubei, China, Email: shahipharmacist@gmail.com

\section{ARTICLE INFO}

Received: 幽 February 23, 2021

Published: 慧 March 03, 2021

Citation: Muhammad Ahmer R, Shireen Aziz MS, Shahid Masood R, Sana S. Social Determinants Influence Physician's Behavior in Prescribing Antibiotics: Factors and Consequences. Biomed J Sci \& Tech Res 34(2)-2021. BJSTR. MS.ID.005535.

Keywords: Physicians; Prescribing Behavior; Social Determinants; Factors

\section{ABSTRACT}

Background: Several social determinants other than scientific knowledge can influence the prescribing behavior of physicians.

Objective: To conduct a literature review on available data to identify social determinants influence physician's behavior in prescribing antibiotics.

Data Source: A literature search was performed using 'PubMed' to identify studies for inclusion and exclusion criteria. The following search terms were used: 'Social determinants' 'Irrational use' 'Inappropriate Use' 'Inappropriate Prescription' 'Factors' 'Consequences' and 'Antibiotics'.

Results: Thirty studies met the inclusion criteria from 80 search results. A total of 6 socials determinants and 20 factors identified. The most frequent social determinants were patients, prescribers, the workplace, caregivers (parents and relatives), and industry and drug regulations.

Conclusion: Our findings showed that several social determinants other than scientific knowledge could influence the prescribing decisions of physicians.

\section{Introduction}

Antibiotics are in use since ancient times. An antibiotic is a type of antimicrobial substance active against bacteria. It is the most important type of antimicrobial agent for fighting bacterial infections, and antibiotic medications are widely used in the treatment and prevention of such infections. They may either kill or inhibit the growth of bacteria. Antibiotics are not effective against viruses such as common cold or influenza. The drugs that are used to kill or inhibit the growth of viruses are termed antiviral drugs [1]. Antimicrobial agents are among the most commonly prescribed medications around the globe. Good antibiotic prescribing practice (GAPP) means using most effective, least toxic and least costly antibiotic for a precise duration. Prescribing drugs recognized as a challenging task and an essential practice, which needs to be continuously monitored, assessed and refined accordingly. Moreover, its base is on the understanding of clinical pharmacology principles, knowledge about medicines and particularly experience of the prescriber. According to World Health Organization (WHO), approximately $80 \%$ of antibiotics are used for the primary care but their inappropriate use causes health hazards [2-4].

Physicians are the primary decision makers in healthcare settings. However, the prescribing decision of physicians is the result of a multitude of intertwined factors and several social determinants involved in it [5-7]. Determining the social determinants that influence physicians' prescribing behavior and decision are the 
most important input to develop practice guidelines and healthcare policy. Thus, the purpose of this article is to determine the social determinants and highlight the factors that influence physicians' behavior in prescribing antibiotics. Therefore, highlighting social determinants and factors that influence physicians' prescribing behavior will help to devise a structured way to rationalize patient care process.

\section{Methods}

\section{Search Strategy}

Search strategy and selection criteria data for this review identified by structured review of 'PubMed'. The following search terms were used: 'Social Determinants' 'Irrational use' 'Inappropriate Use' 'Inappropriate Prescription' 'Factors' 'Consequences' and 'Antibiotics'. All papers reviewed were in the English language. All studies screened based on titles and abstracts to exclude irrelevant articles and the remaining full-text reports further examined to determine whether they met the inclusion criteria.

\section{Eligibility and Inclusion Criteria}

Following studies were eligible if reporting: 1) antibiotics use 2) irrational use 3) inappropriate prescription 4) social determinants 5) factors and 6) consequences. The major inclusion criteria were: 1) studies should be original articles 2) the full text providing enough information 3) the studies should be in English, and 4) published from 2000 to 2020.

\section{Data Items}

We reviewed the following information in the full-text records: authors and year of publication, country where study conducted, study design, sample size and population, social determinants, factors and consequences.

\section{Validity of Selected Articles}

The full text articles were appraise based on the following criteria:

1. Did the study have sound objectives?

2. Did the study mention social determinants influencing prescribing decision?

3. Did the study mention factors influencing prescribing decision?

4. Did the study discuss consequences of irrational prescribing?
5. Did the study describe data sources clearly?

6. Did the study use reliable methods?

\section{Results}

The electronic search based on the screening of title yielded a total of 80 reports from PubMED. The study screening process presented in Figure 1. After assessing the full text articles for eligibility, 17 articles identified eligible for discussion out of 80 . In the first screening process, 50 articles excluded because those did not relate to factors, irrational use, irrational prescription, and consequences. Five review articles also excluded including minireviews. In the next process of screening further 13 papers excluded which did not relate to irrational use, irrational prescription social determinants, factors and consequences. The study selection process illustrated in Figure 1. All the included articles had clear aims and objectives, mentioning social determinants and factors that influence physicians' prescribing behavior clearly, and describing data sources. A total of 6 social determinants and 20 factors identified. Table 1 summarizes the social determinants and factors influence physicians' behavior in prescribing antibiotics.

Table 1: Social determinants and factors influence physicians' behavior in prescribing antibiotics.

\begin{tabular}{|c|c|}
\hline Social determinants & Factors \\
\hline Patients - & $\begin{array}{c}\text { Drug misinformation } \\
\text { Patient demands }\end{array}$ \\
\hline Prescribers - & $\begin{array}{l}\text { Lack of education and training } \\
\text { Inappropriate role models } \\
\text { Lack drug information } \\
\text { Generalization of limited } \\
\text { experience } \\
\text { Misleading beliefs about drugs } \\
\text { efficacy }\end{array}$ \\
\hline Workplace - & $\begin{array}{c}\text { Heavy patient load } \\
\text { Pressure to prescribe } \\
\text { Lack of adequate lab capacity } \\
\text { Insufficient staffing }\end{array}$ \\
\hline Caregivers - (parents, relatives) & $\begin{array}{l}\text { Severity of illness } \\
\text { Duration of infection } \\
\text { Afraid of losing patients }\end{array}$ \\
\hline Drug Regulation - & $\begin{array}{l}\text { Non-essential drugs available } \\
\text { Non-formal prescribers } \\
\text { Lack of regulation enforcement }\end{array}$ \\
\hline Industry - & $\begin{array}{l}\text { Promotional activities } \\
\text { Misleading claims }\end{array}$ \\
\hline
\end{tabular}




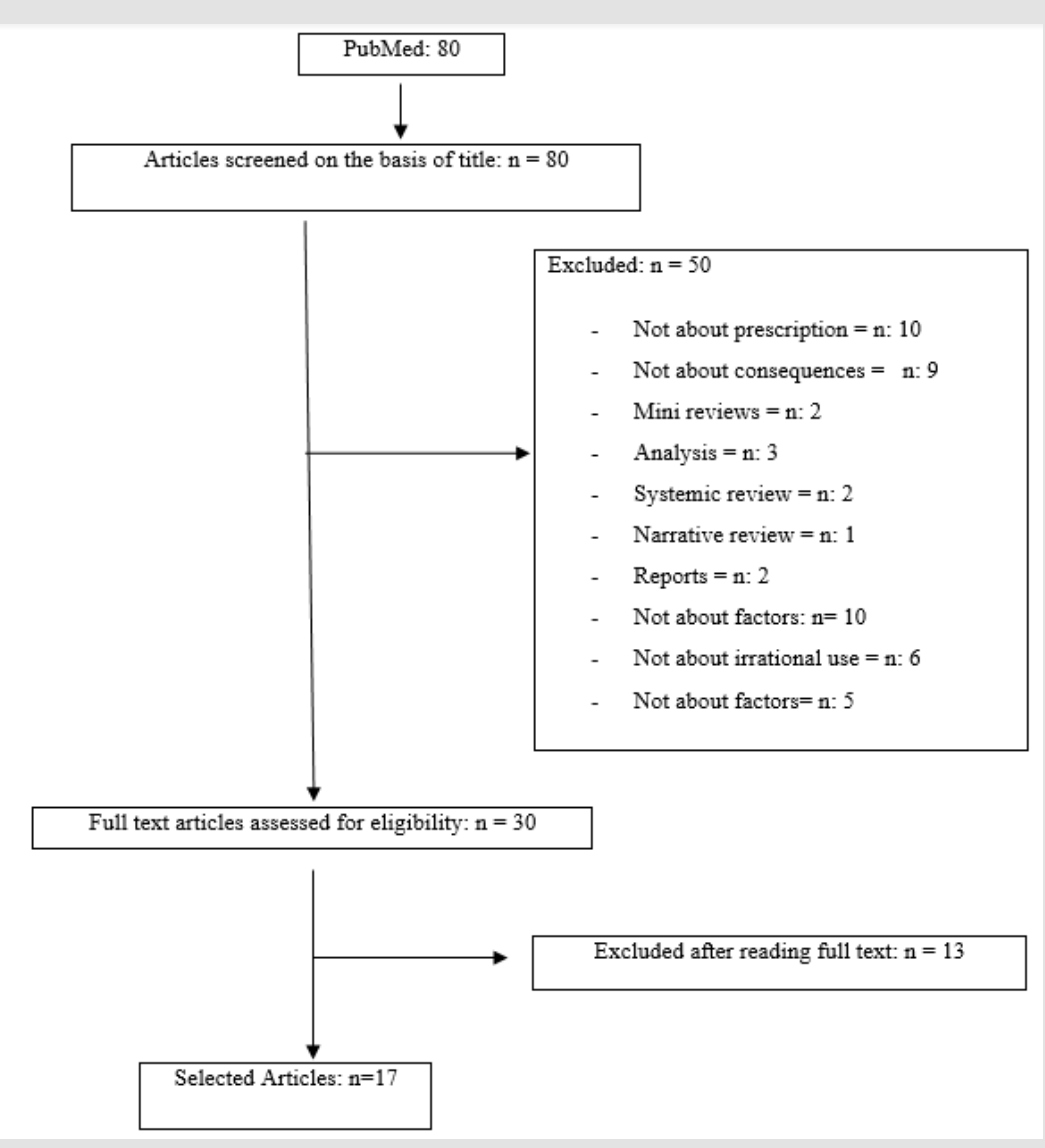

Figure 1: Study selection process.

\section{Discussion}

This was a review of the social determinants that influence physicians' behavior in prescribing antibiotics. When patient visit hospitals and clinics, doctors and physicians prescribe the medicine based on the patients' clinical condition. The clinical condition of the patient includes the sign and symptoms, comorbid conditions and uncertain diagnosis [8,9]. Several social determinants attributed towards physicians' prescribing behavior other than scientific knowledge. The most frequent social determinants include patients, prescribers, workplace, caregivers (parents and relatives), drug regulations and industry. Factors that influence physicians' prescribing behavior in response to these social determinants include patients demands and dissatisfaction, patient misinformation, pressure from patients to prescribe antibiotics regardless of the indication coupled, physicians lack of knowledge and training regarding antibiotics, physicians' nonadherence to treatment guidelines, inappropriate role models, the generalization of limited experience, misleading beliefs about drug efficacy, the burden of work, a load of patients in the workplace, lack of diagnostic facilities, and uncertainty over the diagnosis, insufficient staffing, fear of losing patient from caregivers (parents and relatives), lack of drug regulations, non-essential drugs availability, industrial promotional activities, and financial benefits for physicians [10-21].

Excessive and inappropriate use of antibiotics is a serious threat to the spread of antibiotic resistant (ABR) bacteria [22]. The consequences of antibiotic overprescribing include delays in proper diagnosis and treatment, reduced drug effects, increased side effects, drug resistance, elimination of sources of medicines, increase out-of-pocket payments, dissemination of misconceptions in the common societal culture, reduced patient confidence in the healthcare system, prolonged disease state and even mortality in chronic diseases such as diabetes, hypertension, epilepsy and neurological disorders. To minimize emergence of ABR and reducing consequences of overprescribing, immediate and effective actions needed to improve use of antibiotics. Providing education at community, healthcare, and individual levels is essential to ensure rational use of antibiotics. Special training programs on antibiotic prescribing should be introduced for medical students, junior doctors and GPs. Additionally, pharmaceutical promotion strategies should be monitored by government and stakeholders, including international organizations [23,24].

This review had some limitations worth mentioning. First, the review included only articles published in the English language. Second, the studies included in the review had a different study design, data collection, and analysis technique. 


\section{Conclusion}

It is evident from the various studies that several social determinants influence physicians' behavior in prescribing antibiotics other than scientific knowledge. The most frequent social determinants were patients, prescribers, workplace, caregivers (parents and relatives), and industry and drug regulations. The described social determinants need to be tackled with different angles. These findings can be used in policy development to enhance the prescribing behavior of prescribers.

\section{Acknowledgment}

We are thankful to our colleagues to address the attention to this issue.

\section{References}

1. (2020) NHS. Antibiotics.

2. (2004) The world medicines situation. World Health Organization.

3. Holloway K, L Van Dijk (2011) The world medicines situation. Rational use of medicines. Geneva: WHO.

4. Lu Y, Hernandez P, Abegunde D, Edejer T (2011) The world medicines situation. Geneva: Medicine expenditures World Health Organization $\mathrm{p}$. 35-38.

5. Knight A (2013) Patient-centred prescribing. Aust Prescrib 36: 199-201.

6. Mikhael EM, DN Alhilali (2014) Gift acceptance and its effect on prescribing behavior among Iraqi specialist physicians. Pharmacology \& Pharmacy 5(5).

7. Oshikoya KA, I Oreagba, O Adeyemi (2011) Sources of drug information and their influence on the prescribing behaviour of doctors in a teaching hospital in Ibadan, Nigeria. Pan African Medical Journal 9(1): 13.

8. van Buul LW, van der Steen JT, Doncker SM, Achterberg WP, Schellevis FG, et al. (2014) Factors influencing antibiotic prescribing in long-term care facilities: a qualitative in-depth study. BMC Geriatr 14: 136.

9. Ljungberg C, AK Lindblad, MP Tully (2007) Hospital doctors' views of factors influencing their prescribing. Journal of evaluation in clinical practice 13(5): 765-771.

10. Cole A (2014) GPs feel pressurised to prescribe unnecessary antibiotics, survey finds. British Medical Journal Publishing Group.

11. Gonzalez-Gonzalez C, Vazquez PL, Vazquez J, Pineiro M, Herdeiro MT, et al. (2015) Effect of Physicians' attitudes and knowledge on the quality of antibiotic prescription: a cohort study. PLoS One 10(10): e0141820.

12. McCullough A, J Rathbone, S Parekh, T C Hoffmann, C B Del Mar (2015) Not in my backyard: a systematic review of clinicians' knowledge and beliefs about antibiotic resistance. Journal of antimicrobial chemotherapy 70(9): 2465-2473.
13. Teixeira Rodrigues A, Ferreira M, Lamas MP, Falcao A, Figueiras A, et al. (2016) Determinants of physician antibiotic prescribing behavior: a 3 year cohort study in Portugal. Current medical research and opinion 32(5): 949-957.

14. Dyar OJ, Nathwani D, Monnet D, Gyssens IC, Lundborg CS, et al. (2018) Do medical students feel prepared to prescribe antibiotics responsibly? Results from a cross-sectional survey in 29 European countries. Journal of Antimicrobial Chemotherapy 73(8): 2236-2242.

15. Kerremans J, P Verboom, Stijnen T, van Roijen LH, Goessens W, et al. (2008) Rapid identification and antimicrobial susceptibility testing reduce antibiotic use and accelerate pathogen-directed antibiotic use. Journal of antimicrobial chemotherapy 61(2): 428-435.

16. Huang AM, Newton D, Kunapuli A, Gandhi TN, Washer LL, et al. (2013) Impact of rapid organism identification via matrix-assisted laser desorption/ionization time-of-flight combined with antimicrobial stewardship team intervention in adult patients with bacteremia and candidemia. Clinical infectious diseases 57(9): 1237-1245.

17. (2009) Health Action International. Understanding and responding to pharmaceutical promotion. A practical guide, World Health Organization.

18. Spurling GK, Mansfield PR, Montgomery BD, Lexchin J, Doust J, et al. (2010) Information from pharmaceutical companies and the quality, quantity, and cost of physicians' prescribing: a systematic review. PLoS Med 7(10): e1000352.

19. Lieb K, A Scheurich (2014) Contact between doctors and the pharmaceutical industry, their perceptions, and the effects on prescribing habits. PloS one 9(10): e110130.

20. Lagerlov P, M Loeb, M Andrew, P Hjortdahl (2000) Improving doctors' prescribing behaviour through reflection on guidelines and prescription feedback: a randomised controlled study. BMJ Quality \& Safety 9(3): 159-165.

21. Martens JD, Winkens RAG, van der Weijden T, de Bruyn D, Severens J (2006) Does a joint development and dissemination of multidisciplinary guidelines improve prescribing behaviour: a pre/post study with concurrent control group and a randomised trial. BMC health services research 6(1): 145 .

22. (2017) Global Antimicrobial Resistance Surveillance System (GLASS) report: early implementation 2016-2017, World Health Organization.

23. van der Velden AW, Eefje J Pijpers, Marijke M Kuyvenhoven, Sarah KG Tonkin-Crine, Paul Little, et al. (2012) Effectiveness of physiciantargeted interventions to improve antibiotic use for respiratory tract infections. British Journal of General Practice 62(605): e801-e807.

24. Finch RG, Joshua P Metlay, Peter G Davey, Lee J Baker (2004) Educational interventions to improve antibiotic use in the community: report from the International Forum on Antibiotic Resistance (IFAR) colloquium, 2002. The Lancet infectious diseases 4(1): 44-53. 
ISSN: 2574-1241

DOI: 10.26717/BJSTR.2021.34.005535

Shahid Masood Raza. Biomed J Sci \& Tech Res

(C) This work is licensed under Creative

Submission Link: https://biomedres.us/submit-manuscript.php

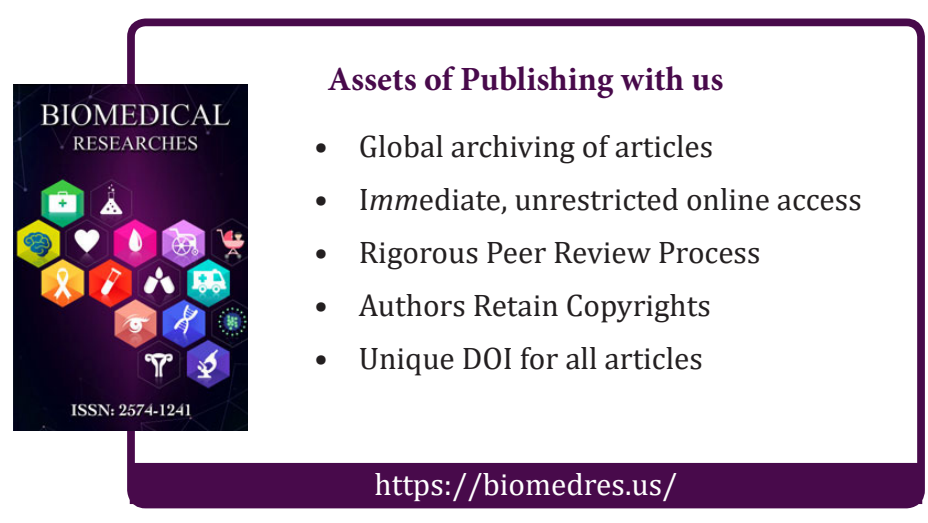

